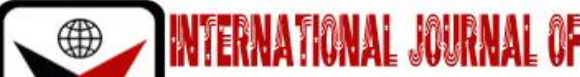

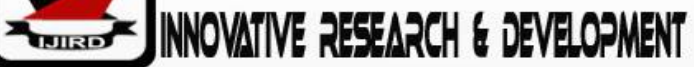

ISSN 2278-0211 (Online)

\section{Role of Early Warning Systems in Flood Disaster Preparedness: Insights from Asamankese in the West Akim Municipality of Ghana}

Frank Jerome Glago
Tutor, Akatsi College of Education and a Native of Ave-Dakpa, Volta Region of Ghana, Ghana
Kafu George Yao
Tutor, Peki College of Education, Resource Development University of Ghana, Ghana
Rejoice Eugenia Ami Sedegah
Tutor, Akatsi College of Education, Winneba, Ghana

\begin{abstract}
:
Rampant flood disasters are increasingly causing devastating impacts of human societies. Early warning systems on the other hand are proactive ways through which the impact of flood disasters can and have been reduced in some jurisdictions. This study sought to assess household's awareness of early warning systems and how effective early warning systems are towards reducing impacts of flood disaster is Asamankese Township in the West Akim municipality of Ghana. A survey was conducted with 200 households in the township and the results show that, residents in Asamankese, a rapidly developing center of commerce in the Eastern region of Ghana, demonstrate a high level of awareness of early warning systems. The findings also show that, for early warning systems to be effective, active participation of community members must be encouraged in the design of early warning systems. There was an observed disjunction between dissemination of early warning system and residents' ability to act per the directives of early warnings received. This study hence recommended that, the local authorities, the government and other key stakeholders should engage the community and device holistic strategies that enable residents to take practical actions towards early warnings to ameliorate the adverse effect of floods.
\end{abstract}

Keywords: Disaster preparedness, early warning systems, west akim municipality

\section{Introduction}

The continuous and persistent increase in the occurrence of disasters poses a substantive danger to the achievement of both sustainable development and poverty reduction initiatives (United Nations Office for Disaster Risks Reduction [UNISDR], 2009). Among disaster events that have gained significant attention in recent times are those caused by floods. Flood hazard is a vicious threat, rather than a natural occurrence when humans interfere with flood plains (Anderson, 1991; Glago, 2019).

On the global scale, flood disaster is phenomenal. According to the United Nations Regional Coordinator in Dakar (October 2007) the worst flooding in 30 years that battered West Africa from July 2007 caused more than 210 death and affected more than 785,000 people (Oppong, 2011 in Glago, 2019).

The aftermaths of flood disasters in Ghana are the large-scale destruction of infrastructure, displacement of people from their dwellings, the loss of human lives, outbreak of diseases, huge loss of investments among other things as the government and disaster management agencies tend to focus on disaster relief activities after disaster occurrences (Oteng-Ababio, 2013).By way of example, in 2007, a catastrophic flood in the northern region of Ghana affected more than 325,000 people, with approximately 100,000 people requiring assistance for the restoration of their livelihoods (GFDRR, 2014).

In addition, the most recent and perhaps the most devastating flood in the history of Ghana occurred in Accra, on $3^{\text {rd }}$ June, 2015 where 159 people lost their lives and several people rendered homeless (Daily Graphic, 2015). NADMO (2010), suggests that although Ghana is vulnerable to certain disasters, flooding has become the major disaster the country has suffered in recent years especially in the urban areas (Kordie, 2013).

Sinclair and Pegram (2003), stated that floods cannot be prevented but their devastating effects can be minimized if advance warning of the event is available. With the large increase in population and increasing urbanization (mainly driven by poverty), there are more people living in informal settlements, which are often on flood plains as this is the only undeveloped land available near cities. The people living in these settlements are those who are most at risk, not only due to their geographical location in the floodplain but also because they do not have the financial resources to recover from 
the damage caused by flooding. Early warning information can, therefore, allow the disaster managers to take stepswhich may significantly reduce theloss of life and damage to property.

\section{Review of Literature}

Early warning system is a broader subject that has been investigated in various ways across the globe. For the purpose of the current study, this section presents related studies that were previously conducted on early warning systems and is presented in four main sections that helps to have a clearer overview of the study objectives and the what has been done in that regards. The sections include people centered early warning systems, access, mechanisms and effectiveness of early warning systems, usefulness of early warning systems on flood disaster management and challenges associated with early warning systems.

\subsection{People Centered Early Warning Systems}

People or dwellers within disaster prone areas have a great responsibility during times of disasters in their vicinity which leads to the involvement in all to ensure the safety of people and the rescue of victims. Early warning system is one way to ensure people are informed prior to disasters occurrence to better manage various disasters including flooding (Wabanhu, 2017). In his survey on the effectiveness of early warning systems for disaster management in Kinondoni municipality in Tanzania, it was revealed that though people may be affected with disasters like flooding, they are unwilling to move from their residence to other places without any genuine reasons such as pre-warning from significant authorities (Wabanhu, 2017). This implies that, though people are rational beings, they may take certain risks that may pose a great burden to themselves and others as well as the government until authorities step in to assist them in their decision making. The study further identified that, people that are served with disaster warnings frequently and given financial assistance are more willing to evacuate their areas of residence than those who do not have such assistance (Wabanhu, 2017; Matthew \& Kapucu, 2008). The media as a point for sending disaster signal messages was identified to be ineffective due to limited access to media devices and lack of education in many flood prone areas of Tanzania (Wabanhu, 2017).

Similar findings were recorded in another survey conducted by Gwimbi (2007) on the effectiveness of early warning systems for the reduction of flood disasters in Zimbabwe. It was recorded that; people are unwilling to move from their settlements which are in flood plains to higher grounds due to previous false alarms that have been given in the area. Warning information are not treated with seriousness and urgency due to messages that were previously given which were seen as false alarms. Their study further revealed that, not only do people refuse to leave their settlements, they were also willing to live with the floods and are interested in early warning information that will help them to better manage the floods rather than moving them away (Gwimbi, 2007). Awareness and preparedness programs, provision of communication equipment for dissemination of information before floods as well as training on warning and evacuation plans were the practices that were more suggested by the people living in flood prone areas. The study suggests that, people in their own accord have little or no plans against disasters like flooding though they are aware that they live within flood prone areas (Gwimbi, 2007; Wabanhu, 2017). This means that, early warning systems including effective and timely dissemination of disaster information will be more appropriate in resolving the burden of disasters.

Being able to determine the level of hazard and also, communicating it to people for effective action is very important in disaster early warning system (Fathani, Karnawati \& Wilopo, 2019). Information can be sent to the local community through sirens and signal warning lamps which gets the people on alert for the necessary action to reduce the negative effects of the event or disaster. Multi stakeholder involvement in the early warning system procedures is an effective way of getting the best things done over a given period of time. This will help escape certain damages that could have been caused if nothing was done (Teuku et al., 2016).

\subsection{Access, Mechanisms and Effectiveness of Early Warning Systems}

There have been varying mechanisms that have been employed in different countries for early warning systems and various ways have been adopted to communicate risk and help people reduce risk and injury during a disaster within their locality. Abdullahi, et al. (2017) in their experiments in Malaysia on a miniaturized water flow and monitoring system which gives information about water level with the help of a sensor showed that, effective deployment of this early warning system will give enough information on water flow rate as well as water rise level which will help reduce casualties arising from flood disasters in the country. It was also identified in Bangladesh that most flood disaster warnings were received by the people from the Bangladesh Meteorological departments through televisions and radio announcements (Fakhruddin et al. 2015). It was however found that, most dwellers in flood prone areas in Bangladesh prefer to take actions based on their personal experiences which they use to forecast what was likely to happen in the future than depending on the information from the meteorological unit (Fakhruddin et al., 2015). In the study, Fakhruddin et al. (2015) concluded that, early warning messages with a lead time of at least ten days will be more effective in reducing damage especially to farmers with regards to crop harvesting. Proper communication procedures and the involvement of varying forms of communication channels to risk population was found to be an effective way if warning is given with at least ten days of lead time with action to reduce damage due to flood (Fakhruddin et al., 2015).

Pozo et al. (2015) also conducted a study on the benefits of continental flood early warning systems to reduce flood disaster impact. The study focused on the policies that are put in place across Europe which deals with flooding and how solutions are designed to mitigate damages from flood disasters. It was shown that, the presence of effective policy framework for flood disaster management, which are effective across all the different phases of policy cycle afforded an important way of reducing flood disasters in Europe over the past decade (Pozo et al., 2015). There had also been 
improvements of flood management through the establishment of the European flood awareness system to manage cross border events (Pozo et al., 2015). The involvement of regional and national water authorities as well as other officials across board in an integrative communication chain will help improve on flood information dissemination that will yields effective action (Pozo et al., 2015; Fakhruddin et al., 2015).

Other studies have shown the involvement of disaster reduction education into the curriculum of the schools in other to help reduce risk associated with disaster. Such countries include Thailand, Indonesia and Sri Lanka (Supprasi et al., 2015). The education on awareness also included workshops and public lectures on disaster reduction. It was also noted that, use of symbolism such as building of memorial places for tsunami, tsunami museums and others which serves as tourist areas was also another strategy adopted to increase disaster awareness (Supprasi et al., 2015).

\subsection{Usefulness of Early Warning Systems on Flood Disaster Management}

There has been a pressing need for the implementation of early warning systems in order to mitigate the damages caused by these disasters over the years across the world. The World Meteorological organization in 2015 showed there is the need for impact-based forecasting and warnings to improve early warning that will yield better forecasting that predicted consequences of hazards for different groups in various sectors for better management.

The negative impact of flood disasters has decreased drastically due to the presence of early warning systems which helped vulnerable populations to take actions before the damage could be caused (Chan, 2012). Chan (2012) showed that, the 1926 floods in Malaysia had destroyed several kilometers of forest lands within the Kelantan and Besut rivers which caused massive damage to Malaysia as a whole. Also, due to the high economic lose experienced in Malaysia due to flooding disasters including the destruction of millions worth of infrastructure, close down of the airport and railways and also lose of millions of dollars used in recovery and restoration. The Malaysian government had installed rainfall stations, telemetric water level stations, flood warning boards, flood sirens and other flood forecasting and warning systems which has resulted in a reduction in the damage caused (Chan, 2012).

Pozo et al. (2015) in their study on the benefits of early warning systems for flood disasters has shown that, there is a reduction in the socio-economic impact of floods especially within the European Union and other parts of the world with the involvement in the global flood early detection. Fakhruddin et al. (2015) also found that, early warning for flood disasters with at least 10 days lead time will work in getting most crops of farmers being harvested before they get washed away by water. This implies that, most farmers when given early warning concerning flood disaster, will act faster in getting most of their crops which will reduce the economic cost involved in a flood disaster (Fakhruddin et al., 2015). However, this could only be achieved through effective communication that will yield effective action with a longer lead time to the event (Fakhruddin et al., 2015).

With the negative effect of flash water flood within Southern Africa of humans and loss of economic value which affects the people involved due to the lack of or insufficient early warning systems, Jubach and Tokar (2016) has shown that, with the help of projects such as delivery of warnings of hydro meteorological hazards, and other related projects, there are reductions in these negative effects especially in terms of economic loss as well as loss of lives.

Also, Pappenberger, Cloke, Parker, Wetterhall, Richardson and Thielen (2015) has identified that, for every euro invested into an early warning system for flood in the Europe, there is a return of 159 euros after twenty years of operation. Educating people on the awareness of disaster risk management could lead to a significant reduction in the negative impact of disaster (Khalid \& Shafiai, 2015)

\subsection{Challenges Associated with Early Warning Systems}

Early warning systems implementation is found to be one of the most effective ways to reduce damage caused by disaster including loss of life, properties, farmlands and vegetative cover which is source of habitat for humans. In recent years, several countries (including China, Malaysia and European countries) have adopted the use of early warning signs for disaster management to improve on the living condition of citizens (Chan, 2012; Sai et al. 2018; Supprasi et al., 2015). There are however, certain challenges that are faced with early warning implementation as shown in various studies conducted in the areas where the early warning system for disaster management is implemented.

In a study conducted by Chan (2012) in Malaysia on the impact of disaster and disaster risk management, it was shown that, early warning system requires interdisciplinary approach into getting better decisions to be taken which most disaster management teams or stations lack. It was also shown that, most departments do not get involved in early warning system implementation to ensure good and sustainable policies are put in place to work efficiently (Chan, 2012). Lack of political will or political fallouts as well as lack of awareness of early warning systems were also challenges of early warning systems that had been recorded. In addition, climate change and the individual problems such as memory loss has also been challenged that early warning implementers often face in the course of running an early warning system for disaster management (Chan, 2012). People easily forget their personal experiences with flood disasters which affects their preparations towards such future events. The lack of social capital has also been one main challenge of implementing early warning systems for disaster management (Chan, 2012).

In a qualitative study by Horita et al. (2016) on the early warning process in disaster management, it was shown that, to effectively implement an early warning system, there is the need for collaborative efforts from people with different specialties within a team. The team may consist of meteorologists, hydrologist, geologist and other disaster management specialist who work with collective effort to make precise decision on hazard and warning communication and dissemination of information to the general public. However, it was shown that, with limited specialists in these fields, early warning systems face a challenge of the lack of data for vulnerable communities which will be used to determine the risk level and help prepare the people adequately for the necessary actions to be taken in time of the disaster to reduce the 
damage that could have been caused (Horita et al., 2016). Another big challenge of early warning system is the changes caused by geological factors (Horita et a., 2016; Sai et al., 2018). Different geographical areas experience different hydraulic conditions which implies that, different warnings should be prepared for the different groups in the community based on their level of hydraulic experience or risk level (Sai et al., 2018).

The lack of technical skills, manpower, resources and the unwillingness for people to engage in volunteering activities for early warning and disaster management activities is a major problem faced by implementers of early warning system as posited by Sai et al. (2018) in their study, towards impact-based flood forecasting and warning in Bangladesh. Another major challenge with early warning system is the tendency of the people to decrease their preparedness level after they have experienced the disaster according to (Fathani et al., 2016). Fathani et al. (2016) showed that, there is a higher likelihood to have a high awareness or preparedness level after a few weeks following the experience of a disaster however, many people tend to fade their preparedness level away with time. Implementing warning system without the involvement of community may be ineffective because community members do not fully understand or know what actions to take if the warning in given (Fathani et al., 2016).

Communication gap between the disaster management team and the community has been recorded as a significant challenge to early warning system by (Khan et al. 2018). The final but most important stage of early warning implementation is the dissemination of warning messages to the communities that are vulnerable for the necessary action to be taken. However, Khan et al. (2018) found that, there is a great gap in getting the message to the people especially when messages are sent through SMS, the people are unable to better understand or take necessary actions. The study further suggested that, loud speakers are used to ensure that, warning messages get to the door step of vulnerable people. Most people are also unconcerned about the issues of disaster and therefore give little or no attention to preventive measures (Khalid \& Shafiai, 2015). This is because, most people think it is the sole responsibility of the local government to see to the management of all disaster problems within the community and so, most sit aloof until the government steps in to address those issues as shown by Khalid and Shafiai (2015) in their study on the effectiveness of early warning systems in Malaysia.

\section{Data and Methods}

\subsection{Profile of Study Area}

Asamankese township is the capital town of West Akimmunicipality, in the Eastern region of Ghana. The topography of the municipality is generallymountainous and undulating. The municipality can becategorised as partly lowland and highland area. The highestpoint is found around the Atiwa range, which is about $1250 \mathrm{ft}$. above sea level and is located between Pabi, Wawase andAsamankese in the northern part of the municipality(Ampadu-Agyei 2009). These conditions place Asamankesetownship in a valley-like landscape. A medium range, risinggradually between $500 \mathrm{ft}$ and $1200 \mathrm{ft}$ above sea level can befound in the eastern part of the municipality. The rest of themunicipality is characterised by relatively lowland areas. Thegeneral elevation of Asamankese is about $500 \mathrm{ft}$. above thesea level (Ampadu-Agyei 2009; http://www.floodmap.net; Glago, 2019). For more detail on the study area, one should refer author's earlier publication of Asamankese in Glago (2019).

\subsection{Sources of Data Collection}

The primary quantitative data for this research was collected through a survey. The survey was aimed at soliciting the perceptions and experiences of residents with flood disasters and particularly their level of awareness and use of early warning systems. Primary qualitative data on the other hand, was collected through the conduct of key informant interviews.

To augment the interviews, two focus group discussions were held with the residents, one with residents from the flood prone areas and the other with residents of the non-flood prone areas. This gave insights into the differences between the awareness and preparedness levels within residents of different ecological zones of the municipality. Secondary data in the form of existing academic literature, magazines, the print media, and reports from various stakeholder institutions in disaster management were used to broaden the understanding of the research area.

\subsection{Sampling}

The sample population was selected from both the Flood Prone Zone and Non-Flood Prone Zones of Asamankese. The rationale was to assess any significant difference that may exist in the levels of awareness of early warning systems in the two ecological zones. For the survey, heads of households were purposively selected as points of contact from each household surveyed. The 200 households comprised of 120 households from the flood prone areas (Old Zongo, Estate and Abaase communities) and 80 households from the non-flood prone areas (Anum, Asamanketewa and Beposo communities). This share was achieved based on proportional representation of the six communities from which households were selected. Secondly, more emphasis was placed on residents of the Flood Prone Zone in order to highlight their plight and make relevant recommendation to appropriate authorities when needed. The two five (5) member, mixed gendered focus group discussions held, represented residents from both the flood prone and non-flood prone areas respectively.

\section{Methods of Data Analysis}

The study employed the analytical tool- Statistical Package for Social Scientist (SPSS)to process the primary quantitative data. With the aid of SPSS software, the house hold responses were coded and entered into a database to 
generate tables for presentation and analysis. More specifically the study used cross-tabulation to assess various relationships, which included respondents' background and their respective ratings on the role of early warning systems in flood disaster management. A Chi-square test of independence was also calculated to test for the hypotheses.

\section{Results and Discussions}

In the flood prone zone of Asamankese, $14.0 \%$ of the respondents were between the ages of 18-25 years, $25.5 \%$ between the ages of 26-33 years, $26.5 \%$ were between the ages of 34-41 years and 34\% were 42 years and above (see Table 1). However, in the case of the non-flood prone zone, about $45.0 \%$ were between the ages of 34-41 years, whiles $27.5 \%$ were 42 years and above (see Fig. 1). A fair proportion of the respondents (about $48.3 \%$ and $46.3 \%$ in flood prone and non-flood prone areas respectively), had at least a secondary school level of education.

\subsection{Access, Mechanisms, and Effectiveness of Early Warning Systems}

Early warning systems are undoubtedly important when it comes to abating flood risks and reducing impacts of flood occurrences. In view of this, the study sought to examine if there are early warning systems in place and if there are, how effective are they. Table 1 shows that out of the $72.5 \%$ of respondents in the flood zone indicated that they have had access to early warning sign, whiles $27.5 \%$ indicated that they have not had access to early warning signs.

\begin{tabular}{|c|c|c|c|c|c|c|c|c|}
\hline \multirow[t]{2}{*}{ Early warning system } & \multicolumn{2}{|c|}{ Flood prone area } & \multicolumn{2}{|c|}{$\begin{array}{l}\text { Non-flood prone } \\
\text { area }\end{array}$} & \multicolumn{2}{|c|}{ Total } & \multicolumn{2}{|c|}{ Chi-square } \\
\hline & $\#$ & $\%$ & \# & $\%$ & $\#$ & $\%$ & $\mathrm{X}^{2}$ & Sig \\
\hline \multicolumn{9}{|l|}{ Access to early warning signs } \\
\hline Yes & 87 & 72.5 & 63 & 78.8 & 150 & 75.0 & & \\
\hline No & 33 & 27.5 & 17 & 21.2 & 50 & 25.0 & & \\
\hline Total & 120 & 100.0 & 80 & 100.0 & 200 & 100.0 & 1.000 & .317 \\
\hline \multicolumn{9}{|l|}{ Medium of early warningsigns } \\
\hline Radio & 61 & 50.8 & 40 & 50.0 & 101 & 50.5 & & \\
\hline Siren & 43 & 35.8 & 19 & 23.8 & 62 & 31.0 & & \\
\hline Megaphone & 16 & 13.4 & 21 & 26.2 & 37 & 18.5 & & \\
\hline Total & 120 & 100.0 & 80 & 100.0 & 200 & 100.0 & 6.596 & .037 \\
\hline \multicolumn{9}{|l|}{$\begin{array}{c}\text { Effectiveness of early warning } \\
\text { signs }\end{array}$} \\
\hline Increase alertness level & 71 & 59.2 & 47 & 58.8 & 118 & 59.0 & & \\
\hline Build confidence level & 37 & 30.8 & 25 & 31.2 & 62 & 31.0 & & \\
\hline Help overcome flood trauma & 12 & 10.0 & 8 & 10.0 & 20 & 10.0 & & \\
\hline Total & 120 & 100.0 & 80 & 100.0 & 200 & 100.0 & .004 & .998 \\
\hline \multicolumn{9}{|l|}{$\begin{array}{l}\text { Usefulness of early warning } \\
\text { signs }\end{array}$} \\
\hline $\begin{array}{c}\text { Reduce impact of flood hazard } \\
\text { on life }\end{array}$ & 78 & 65.0 & 45 & 56.3 & 123 & 61.5 & & \\
\hline $\begin{array}{l}\text { Reduce economic and material } \\
\text { loses }\end{array}$ & 42 & 35.0 & 20 & 25.0 & 62 & 31.0 & & \\
\hline Help identify safe haves & 0 & 0.0 & 15 & 18.7 & 15 & 7.5 & & \\
\hline Total & 120 & 100.0 & 80 & 100.0 & 200 & 100.0 & 24.646 & .000 \\
\hline \multicolumn{9}{|l|}{$\begin{array}{l}\text { Ways of making early warning } \\
\text { system effective }\end{array}$} \\
\hline $\begin{array}{l}\text { Active involvement of } \\
\text { community }\end{array}$ & 78 & 65.0 & 52 & 65.0 & 130 & 65.0 & & \\
\hline Public education on awareness & 25 & 20.8 & 23 & 28.8 & 48 & 24.0 & & \\
\hline $\begin{array}{c}\text { Effective communication } \\
\text { system }\end{array}$ & 17 & 14.2 & 5 & 6.2 & 22 & 11.0 & & \\
\hline Total & 120 & 100.0 & 80 & 100.0 & 200 & 100.0 & 3.988 & .136 \\
\hline \multicolumn{9}{|l|}{$\begin{array}{c}\text { Designing people-centered } \\
\text { early warning system }\end{array}$} \\
\hline Knowledge of the risks & 8 & 6.7 & 17 & 21.3 & 25 & 12.5 & & \\
\hline $\begin{array}{l}\text { Hazard monitoring, analysis } \\
\text { and forecasting }\end{array}$ & 60 & 50.0 & 43 & 53.7 & 103 & 51.5 & & \\
\hline $\begin{array}{c}\text { Dissemination of alerts and } \\
\text { warnings }\end{array}$ & 52 & 43.3 & 20 & 25.0 & 72 & 36.0 & & \\
\hline Total & 120 & 100.0 & 80 & 100.0 & 200 & 100.0 & 12.779 & .002 \\
\hline
\end{tabular}


On the other hand, more than half $(78.8 \%)$ of respondents in the non-flood prone zone indicated that they have had access to early warning signs. It can be inferred from the results that indeed something is been done to reduce the impact of floods in both ecological zones, probably from an institutional point of view and should be given the support needed by all stakeholders in flood risk management.

Further, table 1 depicts how the early warning signs are carried through or transmitted. The result shows that information regarding flood risks have been disseminated through the radio. For instance, $50.8 \%$ and $50.0 \%$ of respondents in the flood and non-flood prone areas respectively received early warning information through the radio. Moreover, $35.8 \%$ and $23.8 \%$ of respondents received early warning information through siren in the flood and non-flood prone areas respectively. The result thus far shows that there are efforts been made to disseminate information to a larger audience and this probably is the reason why a large proportion of respondents indicated that they had access to early warning system or signs. These efforts resonate with the view that early warning systems should be people-centered, focus on mass education and means of communication should be effective. Moreover, residents were also asked how effective these media are in terms of disseminating information on floods and various risks associated with them. As noticed in Table 1, 59.2 \% and $58.8 \%$ of respondents in the flood and non-flood prone areas respectively indicated that its increased alertness level, whiles $30.8 \%$ and $31.2 \%$ in the flood and non-flood prone areas respectively indicated that it built confidence level. In this regard, it can be pointed out that residents in both ecological zones are aware of the relevance or effectiveness of early warning system, which is the third element of the component of early warning system that is dissemination to alert and warn at-risk people of pending disasters (Practical Action, 2010).

On the issue of the usefulness of early warning system, the study identified a number of usefulness associated with early warning systems in flood management. As indicated on Table 1, most respondents (65.0 \%) in the flood prone zone indicated that it reduces the impact of floods on lives. In addition to this, $35.0 \%$ and $25.0 \%$ of respondents in the flood and non-flood prone zone respectively indicated that early warning signs reduced economic and material losses. The result, is an indication that residents in the flood-prone zones are more aware of the importance of early warning system and how it effectively abates disasters compared to those in the non-flood prone zone. However, it is important to indicate that there is a clear distinction between creating awareness through information dissemination and actually enacting policies that build resilience and reduce vulnerabilities of would-be victims. The result thus far shows that residents are aware of their risks, but in terms of building capacities, lots need to be done, particularly from the institutional point of view.

More important also residents were asked how early warning system could be made effective within the respective communities. Table 1 again shows that $65.0 \%$ of respondents in both ecological zones indicated that communities should be involved in making early warning systems effective. On the other hand, whilst $20.8 \%$ of respondents in the flood prone zone acknowledged the importance of public education in early warning system, another $28.8 \%$ of respondents in the non-flood zone also held similar view that public education was vital to the effective early warning system.

In order to better appreciate the differences in impact of public education within the two zones, a chi-square test was conducted at $95 \%$ level of significant using the SPSS software. The results further indicated that there is no significant difference for response in both ecological zones, meaning responses were similar for both ecological zones. This is because the $\mathrm{p}$-value obtained was greater than $0.05\left(\mathrm{X}^{2}=3.988 \mathrm{df}=2 \mathrm{p}\right.$-value $\left.=.136>0.05\right)$. This supports the claim by Practical Action (2010) that early warning system should be effective; community-based, actively involve community members and should have strong public education on and awareness of risks.

In terms of awareness of the people-centered early warning system, Table 1 pointed out that $50.0 \%$ of respondents in the flood prone zone compared to $53.7 \%$ of respondents in the non-flood prone zone indicated that people-centered early warning system should include hazard monitoring, analysis, and forecasting. Also, another $43.3 \%$ in the flood prone zone and $25.0 \%$ in the non-flood prone zone indicated that people-centered early warning system should alert and warn potential victims or the larger proportion of the populace. It must be indicated however that this response was not similar in both ecological zones. Therefore, it can be concluded with certainty that residents in the flood prone areas are more aware of people-centered early warning systems compared to those in the non-flood prone zone. This result is not surprising since it makes much sense to intensify early warning information in more vulnerable locations. However, question is, have these early warning systems been effective in reducing the devastating impacts of floods. The researcher interrogates these issues in the subsequent section of this chapter on the rating of people-centered early warning systems and challenges associated with early warning systems.

\subsection{Rating of People-centered Early Warning System}

To find out if indeed people-centered early warning system has been effective or probably help in addressing flood disasters within the communities, respondents were asked how effective people-centered early warning system is. Figure 1 show the dynamics. 


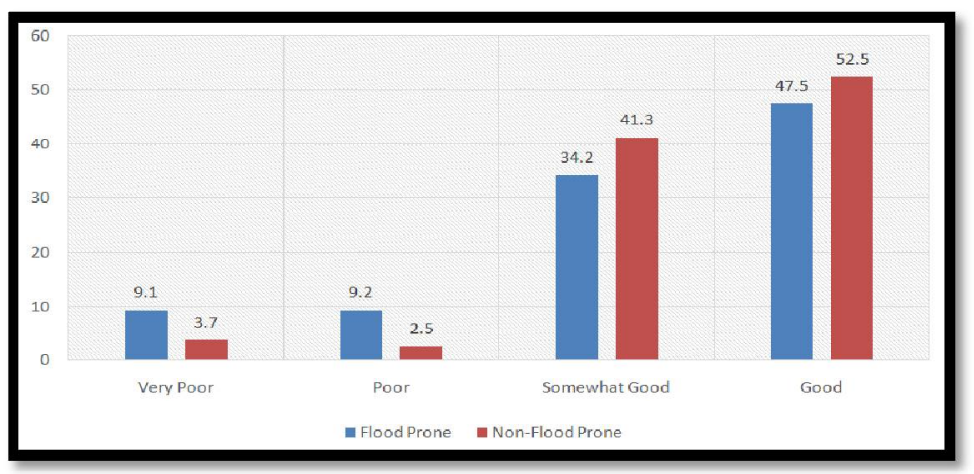

Figure 1: Rating of People-Centered Early Warning System Source: Author's Field Work

As shown in Figure 1, $47.5 \%$ and $52.5 \%$ of respondents indicated it was good in the flood and non-flood prone zone respectively. Also, $34.2 \%$ and $41.3 \%$ of respondents indicated it was somewhat good in the flood and non-flood prone areas respectively. And lastly, $9.2 \%$ and $2.5 \%$ of respondents in the flood and non-flood prone zone respectively indicated that in terms of the effect of the people-centered early warning system, it has been poor. The larger proportion of respondents indicating that it has been good and somewhat good in both ecological zones, corroborate the importance of people-centered early warning system and more importantly it also shows that people are aware of this usefulness. But knowing something to be effective is different from making sure that this effectiveness is actualized in real life experience. The issue is that people are still vulnerable to flood disasters from both social and physical point of view, especially in the flood prone areas as suggested by earlier evidences in Glago, (2019). Therefore, what could be the main hindrance to the actualization of early warning system in flood prone communities like Asamankese.The next section throws more light on the challenges hindering the effective implementation of early warning systems.

\subsection{Challenges Associated with Early Warning System in Asamankese.}

Respondents were asked what challenges there are in the measures put in place in terms of the people-centered early warning system. Summarized in Figure 2, about $32.5 \%$ and $21.3 \%$ of respondents in the flood and non-flood prone zone respectively indicated that information on impending flood are communicated to them but they are not in position to enforce the directives given due to the limited resources. This point is very important as it indicates that perhaps while some effort is being done in disseminating early warning systems in disaster prone communities, the recipient of such information may not be in position to effectively carry through the directives for instance when a directive indicates that they should relocate to safer haven when the situation demands.

Another issue is the lateness of relaying information on impending flood. In addition, $30.0 \%$ of respondents from the flood prone zone indicated the lateness in information dissemination, whiles $50.0 \%$ of respondents indicated same in the non-flood prone zone. Lastly, $37.5 \%$ of respondents in the flood prone zone and $28.8 \%$ in the non-flood prone zone indicated that there was a problem of people adhering to early warning information. That is, as suggested by Chan (2012), interdisciplinary approaches should be used to enhance the effectiveness of early warning systems. Approaches that do not only seek to enhance dissemination of the early warning messages, rather, these approaches should involve measures to uplift residents' capacities to adhere to the early warning directives. It is important to indicate that these challenges severely affect the extent to which strategies for instance, can be deployed to evacuate people from flood-prone areas. Apart from the problem of adherence, which might be attitudinal, the other two are institutional constraints and therefore suggest that more should be done to predict, disseminate and have strategies in place to evacuate people before floods destroy properties, especially in flood prone zones where they are more vulnerable.

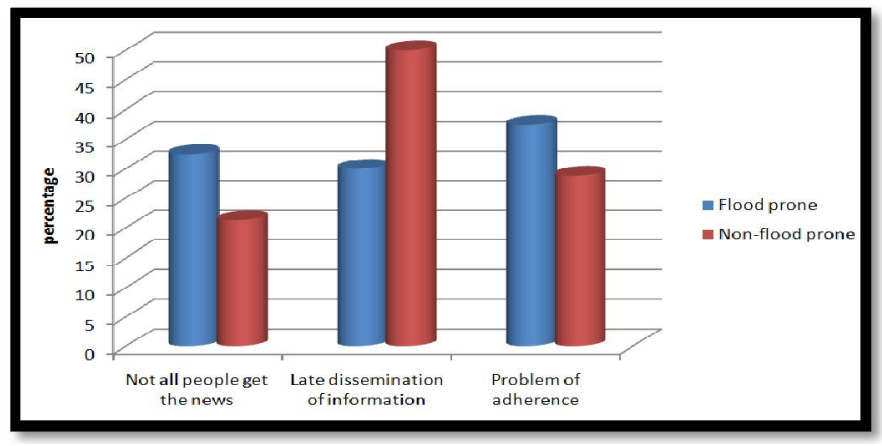

Figure 2: Challenges Associated with Early Warning System Source: Field Survey, 2015

\section{Conclusion}

Flood disasters render communities in Asamankese both physically and socially vulnerable. In addition, residents demonstrate a high degree of awareness of flood disaster early warning systems. Early warning signs are disseminated to 
residents in the communities mainly through radio announcements, by the use of sirens and megaphones in public open spaces.

Asamankese residents assert that, early warnings are useful in building awareness and confidence among local people so flood disaster do not take them by surprise. By getting access to early warnings from radio stations and from the National Disaster Management Organisation division in the municipality, they are able to increase their alertness to floods, reduce material damages and loss of lives that accompany disastrous events of floods, and decrease post flood trauma among victims.

However, although majority of respondents agree to receiving early warning signs prior to flood disasters, evidence shows that some challenges hinder the effectiveness of the early warning signs received. These challenges include late dissemination of early warnings, inefficiencies in the dissemination of early warnings and non-adherence due to lack of capacity to take actions towards early warnings.

\section{Recommendation}

From the findings of this study, the following recommendations are suggested for promoting local and institutional reforms in awareness and preparedness enhancement towards flood hazards.

The government as a matter of urgency should put in place strong early warning system to be managed by institutions like Ghana Meteorological Service, and media and local communication platforms to channel timely, relevant and accurate information on rains, dam water spillage and otherdisaster related information to local people, in a networked fashion to ensure all possible victims get access to the early warnings.

Government and key stakeholders should engage communities in order for them to device livelihood empowerment strategies especially at the flood prone zones in Asamankese, in order for them to take actions towards early warnings delivered to them.

The National Disaster Management Organization (NADMO) should be provided with adequate resources so that they can provide timely and adequate early warning and preparedness efforts to flooding. In addition, resources should also include adequate relief items to help provide adequate relief to people affected by flood events.

\section{References}

i. Abdullahi, S. I., Habaebi, M. H., Gunawan T. S. \& Islam, MD. R. (2017). Miniaturized Water Flow and Level Monitoring System for Food Disaster Early Warning. Materials science and engineering, 260. Doi: 10.1088/1757899X/260/012019.

ii. Chan, N. W. (2012). Impacts of Disaster Risk Management in Malaysia; The Case of floods; in Sawada, Y. and Oum, S. (2011) (eds.), Economic and welfareImpacts of Disasters in East Asia and Policy Responses.ERIA research projects, $8,503-551$

iii. Fakhruddin, S. H. M., Kawasaki, A. \& Babel, M. S. (2015). Community response to flood early warning system: case study in Kaijuri Union, Bangladesh. International Journal of Disaster Risk Reduction. http://dx.doi.org/10.1016/j.ijdrr.2015.08.004.

iv. Fathani T. F., Karnawati D. \& Wilopo W. (2016). An integrated methodology to develop a standard for landslide early warning systems. Nat. Hazards Earth Syst. Sci.

v. Glago, F.J. (2019). Household disaster awareness and preparedness: A case study of flood hazards in Asamankese in the West Akim Municipality of Ghana. Jàmbá: Journal of Disaster Risk Studies, Vol 11, No 1, DOI: https://doi.org/10.4102/jamba.v11i1.789

vi. Gwimbi, P. (2007). The effectiveness of early warning systems for the reduction of flood disasters: some experiences from cyclone induced floods in Zimbabwe. Journal of Sustainable Department in Africa, 8(4).

vii. Horita, E. A. F., de Albuquerque, J. P., Marchezin, V. \& Mendiondo M. E. (2016). A qualitative analysis of the early warning process in disaster management.

viii. Jubach, R. \& Tokar, S. A. (2016). International Severe Weather and Flash Flood Hazard Early Warning SystemsLeveraging, Coordination, Cooperating and Partnerships through a Hydrometeorological Project in Southern Africa. Water, 8(258). Doi: 10.3390/w8060258.

ix. Khalid, S. M. B. \& Shafiai, S.B. (2015). Flood Disaster Management in Malaysia: An Evaluation of the Effectiveness of Flood Delivery System. International Journal of Social Science and Humanity, 5(4).

x. Khan, I., Razzaq, A., Jan, A., Riaz, S. \& Shehzad, N. (2018). An analysis of Community Based Food Early Warning System in the State of Azad Jammu \& Kashmir. Procedia Engineering, 212(2018), 792-800.

xi. Matthew, L. C. \& Kapucu, N. (2008). "Early warning systems and disaster preparedness and response in local government". Disaster Prevention and Management: An International Journal, 17(5), 587-600.

xii. Pappenberger, F., Cloke, H. L., Parker, D.J., Wetterhall, F., Richardson D.S. \& Thielen, J. (2015). The monetary benefits of early flood warnings in Europe. Environmental science \& policy, 51(2015), 278-291.

xiii. Pozo, T. J., Pappenberger, F., Revilla-Romeo, B., Salamon, P., De Groeve, T. \& Hirpa, F. (2015). The benefit of continental flood early warning system to reduce the impact of flood disasters, JCR Science Hub, 97266.

xiv. Sai, F., Cumiskey, L., Weerts, D., Bhattacharya, B. \& Khan, H. R. (2018). Toward impact- based flood forecasting and warning in Bangladesh: a case study at the local level in Sipajganj district. Nat.Hazards Earth Syst. Science, 29. http://doi.org/10.5194/nhess-2018-26.

xv. Wabanhu, R. G. (2017). Examining the effectiveness of early warning system for disaster management in Tanzania: case study of management of floods in Kinondoni Municipality. Dissertation for master's degree. 